\title{
Performance of Sesame Entries under AICRP Testing in Southern Zone of A.P, India
}

\author{
Sabitha Nagubudi*, K. Navya Jyothi and P. Rajasekhar \\ Regional Agricultural Research Station, Tirupati, India \\ *Corresponding author
}

\section{Keywords}

Sesame genotypes, Seed yield, Yield components, Oil content and oil yield

\section{Article Info}

Accepted: 07 November 2019 Available Online: 10 December 2019

\section{A B S T R A C T}

Twenty-three entries of sesame were tested at in the Initial Varietal Trial under AICRP on sesame at RARS, Tirupati during Kharif, 2018 including the two National checks GT 10 and TKG 22, Zonal and Local checks viz., JTS-8 and sarada respectively. Higher variability for plant height, no. of capsules per plant, seed oil content, seed yield, oil yield and low variability for days to $50 \%$ flowering, days to maturity, branches/plant and 1000 seed weight was observed among the genotypes studied. TBS-11 for earliness; LT 15-26, SVT 333 and ACMS 14007 for late maturity; ACMS 14007, DS 18-21, RT 383, RT 385, LT 15-28, VS 15007, TBS 6, TBS 11 for plant height ; DS 18-46 for branches/ plant; RT 384, DS 18-46, JLS 907, TBS 6, LT 15-26, VS 15014 and TBS 11 for number of capsules/plant; SVT 333, DS 18-46 and JCS 2426 for seed weight; JLS 706, JLS 907, LT 15-28, ACMS 14007, RT383, LT 15-26, DS 18-10, DS 18- 46, RT 385, SVT 333, VS 15-007, JCS 2696 and TBS 6 for seed oil content; LT-15-28, RT 385, JCS 706, LT 15-26 and DS 18-46 for seed yield and LT 15-28, DS 18-46, RT 385, JLS 706 and LT 15- 26 for oil yield were found superior. The genotypes viz., LT 15-28, RT 385, JLS 706, LT 15-26 and DS 18-46 were found superior over other genotypes and checks for seed yield, oil content and yield components.

\section{Introduction}

Sesame is primarily grown in West Bengal, Rajasthan, M.P, Gujarat, Andhra Pradesh, Orissa and Tamil Nadu in the country. It is cultivated in all the three seasons but mostly in Kharif season as rainfed crop in the country and in the state. As rabi and summer crop it is raised under irrigated conditions. Its oil contains an oxidant called Sesmol which imparts longer shelf life. Sesame occupies second place after the groundnut crop in area in Andhra Pradesh (Directorate of Economics and Statistics, Govt. of A.P, 2018). It occupies an area of forty thousand hectares both in Kharif and Rabi seasons mostly in West Godavari, Srikakulam, Visakhapatnam, Kadapa, Vizianagaram, Kurnool, Prakasam and Chittoor districts. However, the Sesame crop yields are low in the state compared to 
the National average yields. Moisture stress, Phyllody, Alternaria leafspots, nonavailability of improved varieties with high seed yield, oil content and non pod shattering nature are the major constraints in Sesame cultivation in the state. The present investigation was carried to identify the suitable Sesame varieties among the genotypes developed at the Nation level for cultivation in the state of Andhra Pradesh.

\section{Materials and Methods}

An initial varietal trial with 23 entries including checks under AICRP on Sesame was conducted at Regional Agricultural Research Station, Tirupati during Kharif, 2018 to identify location specific potential Sesame genotypes suitable for light soils of Southern Zone of Andhra Pradesh. The experiment was laid out in a Randomised block Design with three replications.

Each entry was raised in six rows of five meters length adopting $30 \times 10 \mathrm{~cm}$ spacing. Recommended dose of fertilizers@40:20:20 $\mathrm{kg} \mathrm{NPK/ha} \mathrm{was} \mathrm{applied} \mathrm{as} \mathrm{basal} \mathrm{at} \mathrm{the} \mathrm{time} \mathrm{of}$ sowing. Cultural practices and crop protection measures were adopted as per the recommendations of ZREAC for Southern Zone. Data were collected on days to $50 \%$ flowering, days to maturity, plant height $(\mathrm{cm})$, branches/plant, No. of capsules/plant and 1000 seed weight during crop growth and at harvest.

Oil content in seed was determined following Nuclear magnetic resonance method. Oil yield per hectare was calculated based on percent seed oil and seed yield. Seed yield and Oil yield were expressed as $\mathrm{kg} / \mathrm{hectare}$. The analysis of variance was carried out as per the standard statistical procedures using the OPSTAT (version 8) software. To establish the magnitude of the variation among cultivars, comparison of means was made with at 5 per cent level of significance.

\section{Results and Discussion}

The genotypes tested differed significantly for all the characters studied. Significant high variation among the sesame genotypes was observed for plant height, capsules/plant, seed oil content, oil yield and seed yield while a narrow range of variability was noted for days to $50 \%$ flowering, days to maturity, branches/plant and 1000 seed weight. The results of the experiment are presented on character wise (Table 1).

\section{Days to $50 \%$ flowering}

It varied from 35 (TBS 11) to 45 (ACMS 14007, JLS 706, JCS 2696) with a mean value of 40 days. Among the genotypes, TBS 11 (35) was found to be significantly early in flowering compared to the best National checks GT 10 (39) and TKG 22 (38) but on par with the Zonal check JTS 8 (36).

\section{Days to maturity}

The character ranged from 76 (TBS-11) to 88 (ACMS 14007 and JLS 706) with a general mean of 82 days. The genotypes viz., TBS 11(76), LT-15-18 (79) and VS 15007(79) were found to be on par with the best national check TKG20 (78), zonal check JTS 8(76) and the local check Sarada (80). The early maturing genotypes viz., TBS 11, LT15-18, and VS 15007 may be useful in breeding early maturing varieties or may be utilised in intensive cropping systems or under late sown conditions. The low variability noted for days to flowering and days to maturity is in agreement with results of Bharathi et al., (2014), Abate and Mekbib (2015) and Hika et al., (2015).

\section{Plant height (cm)}

A mean value of $77.7 \mathrm{~cm}$ was recorded for this character it ranged from 64.8 (VS 15014) to 
$92.6 \mathrm{~cm}$ (RT 385). The genotypes viz., RT 385, VS 15-007, TBS 6, TBS 11 have recorded significantly higher plant height over the best National checks TKG $22(75.4 \mathrm{~cm})$ and GT 10 $(76.1 \mathrm{~cm})$ while DS 18-21 (68.7), LT 1521(69.5), SVT333(64.8), VS15014(64.8), DS 18-10 (70.5) recorded moderate plant height. The genotypes with moderate plant height may utilised as source in breeding varieties for cultivation under rainfed conditions during kharif. Higher variability for plant height as observed in the present was also reported by Chandra Mohan (2011 and 2014) in sesame.

\section{Number of branches/ plant}

A Narrow range of variation was noted among the genotypes for branches/plant. Mean value for branches /plant recorded in the trial was 2.5. The character varied from 2.0 (DS 18-21, RT 383, JLS706, AT 382, LT 15-16. GT 10, DS 18-10, JLS 907, LT 15-26, RT 385, JCS 2696 and TBS 6) to 5.0 (local check Sarada). None of the genotypes were found superior to best National check TKG 22 (3.0) and Local check (5.0). However, DS 18-46 (4.0) recorded branches on par with the local check Sarada (5.0). DS 18-46 may serve as donor for increasing branches per plant.

\section{Number of capsules/ plant}

The character varied from 20 (DS 18-10, LT 15-26) to 37 (RT 384 and DS 18-46) among the genotypes tested in the trial. A general mean of 30.0 was recorded for number of capsules. The genotypes viz., RT 384, DS 1846, VS 15-014, JTS 907, TBS6, TBS 11, JLS 907, LT 15-26, RT 385, LT 15-28, SVT 333, VS 15014, JCS 2420 have recorded significantly more number of capsules/plant compared to the national check TKG 22 (30) and GT 10 (25) and Zonal check (29). These genotypes can be used as sources for increasing the number of capsules are the major yield determining component in sesame. As noted in the present study Bharathi et.al 2014 also recorded similar results of higher variation for number of capsules per plant in sesame.

\section{0 seed weight $(g)$}

A general mean of $2.3 \mathrm{~g}$ was recorded for this character. Variability for seed weight was found to be low among the genotypes. It ranged from 2.0 (TBS-6, JCS 2696, JLS 706, LT 15-16, ACMS 14007, DS 18-21) to $3.0 \mathrm{~g}$ (JTS-8, LT 15-28 and DS 18-46). The genotypes viz., LT 15-28, DS 18-46 recorded significantly higher 1000 seed weight than the National checks GT 10 (2.1g), TKG 22 (2.3 g, and Local check 2.6g). However, they were found to be on par with the Zonal check JTS 8 (3.0g).

\section{Oil content $(\%)$}

A moderate to high range of variability was noted for seed oil content. The character varied among entries from 35.4 (DS 18-21) to 51.4 (LT 15-28) with general mean of 41.9 percent. Among the entries viz., JLS 706, JLS 907, LT 15-28, ACMS 14007, RT383, LT 1526, DS 18-10, DS 18- 46, RT 385, SVT 333, VS 15-007, JCS 2696 and TBS 6 recorded significantly more oil content compared to the National checks GT $10(40.5 \%)$ and TKG 22 (38.3\%). However, JLS 706, JLS 907 and LT 15-28 were found to be on par with Zonal check (51.1) and the local check (50.5) for oil content.

\section{Seed yield (kg/ha)}

Higher variability for seed yield was recorded among the genotypes studied. The character varied from 244.8 (TBS 11) to 489.5(RT 385) and the general mean recorded was 346.2 $\mathrm{kgha}^{-1}$. 
Table.1 Performance of sesame genotypes for seed yield and yield components

\begin{tabular}{|c|c|c|c|c|c|c|c|c|c|c|}
\hline S.N o & Genotypes & $\begin{array}{c}\text { Days to } \\
50 \% \\
\text { flowering }\end{array}$ & $\begin{array}{l}\text { Days to } \\
\text { maturi } \\
\text { ty }\end{array}$ & $\begin{array}{c}\text { Plant } \\
\text { Heig } \\
\text { ht } \\
(\mathbf{c m})\end{array}$ & $\begin{array}{c}\text { Number } \\
\text { of } \\
\text { Branch } \\
\text { es/ plant }\end{array}$ & $\begin{array}{c}\text { Number } \\
\text { of } \\
\text { capsules } \\
\text { / plant }\end{array}$ & $\begin{array}{c}1000 \\
\text { Seed } \\
\text { Weight } \\
\text { (g) }\end{array}$ & $\begin{array}{c}\text { Oil } \\
\text { Conten } \\
t(\%)\end{array}$ & $\begin{array}{c}\text { Seed } \\
\text { yield } \\
(\mathbf{k g} \\
\left.\text { ha- }^{1}\right) \\
\end{array}$ & $\begin{array}{c}\text { Oil } \\
\text { yield } \\
(\mathbf{k g} \text { ha- } \\
\mathbf{1} \text { ) }\end{array}$ \\
\hline 1 & ACMS-14007 & 45 & 88 & 84.3 & 3.0 & 30 & 2.0 & 42.3 & 370.3 & 151.83 \\
\hline 2 & DS-18-21 & 40 & 81 & 68.7 & 2.0 & 22 & 2.0 & 35.4 & 370.3 & 131.71 \\
\hline 3 & RT-383 & 40 & 82 & 85.3 & 2.0 & 26 & 2.1 & 44.0 & 332.6 & 148.14 \\
\hline 4 & JLS-706 & 45 & 88 & 74.3 & 2.0 & 25 & 2.0 & 51.3 & 382.8 & 194.94 \\
\hline 5 & AT-382 & 42 & 83 & 79.1 & 2.0 & 23 & 2.1 & 41.2 & 307.5 & 129.08 \\
\hline 6 & LT-15-16 & 40 & 82 & 76.3 & 2.0 & 20 & 2.0 & 43.4 & 351.5 & 151.18 \\
\hline 7 & GT10(C) & 39 & 80 & 76.1 & 2.0 & 25 & 2.1 & 40.5 & 313.8 & 131.25 \\
\hline 8 & DS-18-10 & 39 & 82 & 70.5 & 2.0 & 20 & 2.2 & 48.2 & 301.2 & 147.89 \\
\hline 9 & RT-384 & 42 & 85 & 72.1 & 3.0 & 37 & 2.1 & 37.2 & 370.3 & 140.79 \\
\hline 10 & JLS-907 & 38 & 82 & 73.7 & 2.0 & 35 & 2.2 & 51.1 & 313.8 & 157.90 \\
\hline 11 & LT-15-26 & 43 & 86 & 69.5 & 2.0 & 34 & 2.2 & 37.8 & 451.9 & 171.09 \\
\hline 12 & DS-18-46 & 39 & 82 & 73.4 & 4.0 & 37 & 3.0 & 44.0 & 464.4 & 212.78 \\
\hline 13 & TKG22(C) & 38 & 78 & 75.4 & 3.0 & 30 & 2.3 & 38.3 & 451.9 & 175.11 \\
\hline 14 & RT-385 & 40 & 83 & 92.6 & 2.0 & 30 & 2.3 & 41.4 & 489.5 & 206.20 \\
\hline 15 & LT-15-28 & 39 & 79 & 81.3 & 3.0 & 31 & 3.0 & 51.4 & 401.7 & 202.15 \\
\hline 16 & SVT-333 & 40 & 86 & 68.5 & 3.0 & 32 & 2.1 & 46.0 & 276.1 & 131.68 \\
\hline 17 & VS-15014 & 40 & 80 & 64.8 & 3.0 & 31 & 2.2 & 38.4 & 357.7 & 139.75 \\
\hline 18 & JCS-2420 & 40 & 85 & 75.7 & 3.0 & 34 & 2.6 & 39.5 & 313.8 & 125.13 \\
\hline 19 & VS-15007 & 40 & 79 & 86.0 & 3.0 & 30 & 2.2 & 43.3 & 288.7 & 120.12 \\
\hline 20 & JCS-2696 & 45 & 85 & 75.5 & 2.0 & 33 & 2.0 & 42.7 & 276.1 & 117.48 \\
\hline 21 & TBS-6 & 40 & 82 & 91.1 & 2.0 & 35 & 2.0 & 48.9 & 288.7 & 135.50 \\
\hline 22 & TBS-11 & 35 & 76 & 87.9 & 3.0 & 36 & 2.1 & 40.8 & 244.8 & 99.08 \\
\hline 23 & Zonal Check & 36 & 76 & 86.1 & 3.0 & 29 & 3.0 & 51.1 & 320.1 & 157.65 \\
\hline \multirow[t]{4}{*}{24} & Local Check & 39 & 80 & 83.6 & 5.0 & 34 & 2.6 & 50.5 & 269.9 & 136.13 \\
\hline & General Mean & 40 & 82 & 77.7 & 2.5 & 30 & 2.3 & 43.7 & 346.2 & 150.61 \\
\hline & CD at $5 \%$ & 2.45 & 3.35 & 12.33 & 1.15 & 8.7 & 0.051 & 1.038 & 59.18 & 4.19 \\
\hline & CV & 3.65 & 2.46 & 7.81 & 12.62 & 6.53 & 1.36 & 1.433 & 12.81 & 1.69 \\
\hline
\end{tabular}

Among the genotypes studied, LT-15-28, RT 385, JCS 706, LT 15-26 and DS 18-46 recorded significantly higher seed yield compared to the National check GT 10(313.8 $\left.\mathrm{kgha}^{-1}\right)$. However, they were found on par with the best national check TKG 22 (459.1 $\mathrm{kgha}^{-1}$ ). Higher variability recorded for seed yield in the study is in tune with the findings of Abate and Mekbib (2015).

\section{Oil yield $\left(\mathrm{kgha}^{-1}\right)$}

The oil yield among sesame genotypes varied from $99.08 \mathrm{kgha}^{1}$ (TBS 11) to $212.78 \mathrm{kgha}^{-1}$ (DS 18-46) with an average value of 150.61 $\mathrm{kgha}^{-1}$. The genotypes viz., LT 15-28, DS 18 46, RT 385, JLS 706 and LT 15-26 have recorded significantly higher oil yield compared to other genotypes and the best National checks GT $10\left(131.25 \mathrm{~kg} / \mathrm{ha}^{-1}\right)$, TKG 
$22\left(175.11 \mathrm{~kg} / \mathrm{ha}^{-}{ }^{1}\right)$, Zonal check (157.65 kgha- $^{-1}$ ).

Higher variability for plant height, number of capsules per plant and seed yield recorded in the present study were also reported in Sesame by Chandra Mohan (2011 and 2014); Bharathi et al., 2014) and Abate and Mekbib (2015). The low variability noted for days to flowering and days to maturity is in agreement with the results of Bharathi et al., (2014), Abate and Mekbib (2015) and Hika et al., (2015) in sesame.

The character specific genotypes viz. TBS-11 for earliness; JLS 706, ACMS 14007 for late maturity; DS 18-46 for branches/plant; RT 384, DS 18-46, JLS 907, TBS 6, LT 15-26, VS 15014 and TBS11 for number of capsules/plant; SVT 333, DS 18-46 and JCS 2426 for seed weight; JLS 706, JLS 907, LT 15-28, ACMS 14007, RT383, LT 15-26, DS 18-10, DS 18- 46, RT 385, SVT 333, VS 15007, JCS 2696 and TBS 6 for seed oil content; LT-15-28, RT 385, JCS 706, LT 15-26 and DS 18-46 for seed yield and LT 15-28, DS 1846, RT 385, JLS 706 and LT 15- 26 for oil yield may be utilized as donors in crop improvement.

The present study revealed the existence of higher variability for plant height, no. of capsules per plant, seed oil content, seed yield and oil yield and low variability for the days to $50 \%$ flowering, days to maturity, branches/plant and 1000 seed weight Among the 23 genotypes tested for their performance TBS-11, LT 15-28 and VSI5007 for earliness; DS 18-21, LT 15-26, SVT 333, VS 15014, and DS 18-10 for moderate plant height ; DS 1846 for branches/ plant; RT 384, DS 18-46, JLS 907, TBS6, LT 15-26, VS 15014, RT 385, LT 15-28, SVT 333, JCS 2420 and TBS 11 for number of capsules/plant; LT 15-28 and DS 18-46 for seed weight; JLS 706, JLS 907 and LT 15-28 for seed oil content; LT-15-28, RT
385, JCS 706, LT 15-6 and DS 18-46 for seed yield and LT 15-28, DS 18-46, RT 385 and JLS 706 for oil yield were found superior. The character specific genotypes identified in the present investigation may be utilized as donors in crop improvement. Based on major yield and yield components viz., no. of capsules per plant, seed yield, oil content and oil yield LT 15-28, RT 385, JLS 706, LT 15-26 and DS 1846 identified in the present study may be recommended for general cultivation after thorough testing in farmers fields in on farm testing.

\section{References}

Abate,M. and F. Mekbib, 2015. Assessment of genetic variability and character association in Ethiopian low altitude Sesame (Sesamsum indicum L) genotypes. Journal of Advanced Studies in Agriculture Biodiversity and Environmental Sciences. 2(3):55-66.

Agricultural Statistics at a Glance - Andhra Pradesh. 2018. Publication by Directorate of Economics \& Statistics, Govt. of Andhra Pradesh. pp: 25-26

Bharathi, D; Thirumala Rao, V; Chandramohan, Y; Bhadru, D and Venkanna. V. 2014. Genetic variability studies in Sesame (Sesamum indicum L). International Journal of Applied Biology and Pharmaceutical Technology. (4): 31-33.

Chandra Mohan, Y. 2011. Genetic variability, Genetic advance and character association in Sesame (Sesamum indicum L.). Crop Research. 42(10): 259-262.

Chandra Mohan Y. 2014. Variability and genetic divergence in Sesame (Sesamum indicum L). International Journal of Applied Biology and Pharmaceutical Technology. 4. 222225.

Hika, G. ;Gelela, N. and Jalela Z. 2015. 
Genetic variability, heritability and Genetic advance for phenotypic traits studies in Sesame (Sesamum indicum L) populations from Ethiopia. Science and Arts Research journal. 4(1)20-26.

O.P Sheoran "Hisar statistical package for Agricultural scientists (OPSTAT)," CCSHAU.

http://www.202.141.47.5/opstat/index. asp.

Soundharya, B; Hemalatha, V; Shobha Rani. Tand D. Srinivasa Chary. 2016. Genetic variability, heritability and Genetic advance for phenotypic traits in Sesame (Sesamum indicum L) genotypes. Progressive Research :ISSN: 2452-6003.

\section{How to cite this article:}

Sabitha Nagubudi , K. Navya Jyothi and Rajasekhar, P. 2019. Performance of Sesame Entries under AICRP Testing in Southern Zone of A.P. Int.J.Curr.Microbiol.App.Sci. 8(12): 419-424. doi: https://doi.org/10.20546/ijcmas.2019.812.055 